\title{
COMPRA E DISTRIBUIÇÃO DE MEDICAMENTOS: PERCEPÇÃO DE FUNCIONÁRIOS DE UMA REDE DE ATENÇÃO PRIMÁRIA À SAÚDE DO INTERIOR DO ESTADO DE SÃO PAULO.
}

Carmen Maria Casquel Monti Juliani*

JULIANI, C.M.C.M. Compra e distribuição de medicamentos: percepção de funcionários de uma rede de atençăo primária à saúde do interior do Estado de Săo Paulo. Rev.Esc.Enf.USP, v. 29, n. 3, p. $267-85$, dez. 1995.

O presente estudo trata do processo de compra e distribuicão de medicamentos para Unidades Básicas de Saúde em um município do interior do estado de São Paulo. Tece algumas considerações gerais acerca da Política Nacional de medicamentos no Brasil, ressaltando aspectos relativos à sua estruluração no Sistema Único de Saúde.

UNITERMOS: Política de medicamentos. Administração em Enfermagem. Administraça de materiais. Compra e distribuiçăo de medicamentos.

\section{INTRODUÇÃO}

A iniciativa para realização do presente trabalho foi gerada em parte pela expectativa de contribuição que o mesmo possa trazer à prática do ensino de graduação em enfermagem, já que trata-se de um dos temas trabalhados em Administração de Serviços de Saúde. Além disso, assume, nos dias atuais, de importante etapa na consecução dos objetivos assistenciais propostos na política do Sistema Único de Saúde.

Assim, o presente estudo analisa a percepção da equipe de saúde que trabalha no processo de compra e distribuição de medicamentos ao nível da assistência primária à saúde.

* Mestranda da Escola de Enfermagem da USP.

Rev.Esc.Enf.USP, v.29, n.3, p.267-85, dez. 1995. 
Faz-se mister, inicialmente, a contextualização de alguns aspectos da Política Nacional de medicamentos no Brasil, para depois adentrarmos na operacionalização do presente trabalho.

A Lei Orgânica da Saúde (Lei 8.080 de 19/09/1990) traz em seu capítulo 1 , artigo 6o. que estão incluídas no campo de atuação do Sistema Único da Saúde a execução de assistência terapêutica integral, inclusive farmacêutica. (BRASIL, 1990)

Entre algumas das metas estabelecidas no Plano Quinquenal de Saúde 1990/95 podemos encontrar: prestação de assistência farmacêutica essencial (produtos da linha da Relação Nacional de Medicamentos Essenciais RENAME) a $100 \%$ da populaçāo brasileira com renda insuficiente para custear medicamentos ( $70 \%$ da população total), até 31 de agosto de 1995 e redução de perdas no sistema e também nos custos de aquisição, até 31 de agosto de 1990.(BRASIL, 1991)

Também a declaração de Alma Ata - 32a. Assembleia Geral da Organização Mundial da Saúde (OMS), indica, entre os dez pontos que devem ser incluídos entre os cuidados primários, o fornecimento de medicamentos básicos. (CUNIIA, 1987)

Observamos, em nossa experiência prática, ao nível de rede primária de atenção à saúde, que em um país capitalista em desenvolvimento como o Brasil, que incorpora cada dia mais tecnologia e medicalização nos Serviços de Saúde, consequência provável da industrialização crescente centrada na produção, que as despesas com medicamentos apresentam custos crescentes. Não podemos nos esquecer que, aliado a esse fator, o empobrecimento da população, a deterioração nas condições de vida e até mesmo o "pesado marcketing" das indústrias farmacêuticas, reforçam essa problemática.

Um dado estarrecedor te a verificação de que em 1970 era estimado um representante de laboratório para cada três médicos no Brasil, enquanto que em países como os EUA, Filândia, Inglaterra, Suécia e Noruega, essa relação é respectivamente 1:14, 1:17, 1:18, 1:24 e 1:32. (BERMUDEZ, 1992)

$\Lambda$ esse propósito, convém lembrar o esforço da OMS, em votar e aprovar o Código de Ética para as empresas produtoras de leite em pó, que através de meios sutis de indução, estavam levando à substituição do aleitamento materno pelo leite artificial, com prejuízos para milhares de crianças em todo o mundo, em especial as do terceiro mundo. (SARAIVA, 1983)

Embora a distribuição de medicamentos não seja solução única aos problemas de saúde, já que os mesmos advém das condiçōes de vida da população, reconhecemos a importância da sua distribuição gratuita à população. Afinal, como negar, por exemplo, a uma mãe, já tão expropriada das demais condições, um medicamento, quando esta chega até você com uma criança enterma? 
Além disso, convém lembrar que o sistema de saúde brasileiro é calcado em um modelo médico-cêntrico, onde, não raro, o paciente termina a consulta médica com uma receita na mão. Cerca de $80 \%$ das consultas médicas implicam na prescrição de um ou mais medicamentos, sendo comum que a consulta médica seja realizada visando a repetição de uma prescrição anterior. (Balint et.al.apud CORDEIRO, 1985)

O forte, e praticamente exclusivo, embasamento das políticas de saude na comunidade médica, adotadas historicamente por governos brasileiros, ignorando a existência de outros profissionais, acarreta distorções que se refletem na demanda de produtos que não são, necessariamente, os de maior economicidade social. O reconhecimento da necessidade de implantação de equipes multiprofissionais integradas em ações de saúde abrirá campo para um melhor aproveitamento dos recursos naturais do país e uma libertação dos grilhões do colonialismo técnico-científico que caracteriza o setor de medicamentos no Brasil. (CUNHA, 1987)

Segundo SARAIVA (1983) a Central de Medicamentos (CEME), criada em junho de 1971, teve como objetivo básico a gradativa ampliação de assistência farmacêu tica às classes de reduzido poder aquisitivo. Ao instituir a CEME o Governo levou em conta a realidade, todos os dias observada, de que, sem a possibilidade de aviamento da receita, a consulta médica se torna in ócua para uma grande parte da população.

Ainda o mesmo autor, analisando historicamente a evolução da indústria farmacêutica no Brasil, aborda alguns problemas enfrentados:

- Desnacionalização do setor a partir da década de 40, com a transformação da terapêtica médica, que passou a se apoiar intensamente em antibioticos e produtos de síntese química;

- A indústria farmacêutica, como qualquer outra, tem propósito mercantilista, dirigicla para o lucro privado e só secundariamente, voltada para uma das mais dramáticas necessidades do Homem: a superação da doença;

- Divorciamento entre a destinação dos produtos ofertados e o quadro nosologico do país;

- Utilização da população dos países sub-desenvolvidos como massa de teste para substâncias desenvolvidas em outros países;

Também um documento do Ministério da Saúde de janeiro/93 intitulado " $\Lambda$ Assistência Farmacêutica (iovernamental e a Estabilização do Mercado de Medicamentos", aponta para algumas dificuldades, entre as quais citaremos as mais importantes:

- Nos últimos anos, a CEMÉ reduziu a $20 \%$ os seus níveis históricos de cobertura da demanda de medicamentos para o Sistema Único da Saúde;

- Corrupção e descompromisso das administrações; 
- Perdas estimadas em $40 \%$ por deficiência na rede de distribuição ou superestimacão da demanda para compensar descontinuidade no abastecimento;

- O Brasil é extremamente dependente do exterior, sendo que apenas 20 \% do mercado está sob domínio de empresas de capital nacional;

- Desestímulo a atividades de Pesquisa e desenvolvimento voltadas para a autosuficiência brasileira em medicamentos;

- Aumento das demandas governamentais sem a correspondente alocação orcamentária;

- Desregulamentação da economia, com o fím do controle de preços de medicamentos.

CORDEIRO (1985) aponta ainda que:

- A evolução dos gastos pela CEME evidencia a predominância da propaganda de aquisição e distribuição de medicamentos, enquanto programas de modernização de laboratorios oficiais e de pesquisa mantem-se estacionários ou sofrem leves incrementos;

- Não se ampliou e reaparelhou o orgão do Ministério da Saúde encarregado do controle de qualidade ao nível nacional, o que favorece a persistência, no mercado, de medicamentos de baixa eficácia, potencialmente perigosos e, principalmente, de associações medicamentosas ineficazes;

- Os medicamentos, particularmentes os de "largo espectro" e sintomáticos, podem estar assumindo relevância nas estratégias da consulta médica, pela necessidade de aumentar a produtividade dos serviços, contribuindo para a reducão do tempo da relação médicopaciente. O paciente 6 medicalizado no sentido de resolver rápida e "cientificamente" o problema.

A influência da produção material enquanto determinante econômico no processo de medicalização da saúde fica claro, quando analisamos fatores históricos e as consequências da industrialização crescente, verificadas nos dias atuais.

Após a contextualização de algumas vertentes da Política de Medicamentos no Brasil, esclarecemos que o presente trabalho objetivou conhecer a percepção de trabalhadores de saúde, envolvidos no processo de compra e distribuição de medicamentos fornecidos a uma Rede Municipal de Saúde, voltada à atenção primária, a fim de resgatarmos sua compreensão acerca do próprio processo de trabalho e compartilharmos de suas 
experiências. $\Lambda$ distribuição de medicamentos na referida rede de scrviços de saúde tem como fornecedores básicos o Escritório Regional de Saúde (ERSA) e o próprio município, que, além de fornecedor, é responsável pela guarda e distribuição desses insumos. Mais adiante, comentaremos um pouco mais sobre o processo de distribuição dos medicamentos.

A autora acredita que o estudo permita reflexões acerca da assistência prestada à população e proporcione subsídios para o ensino de graduação em enfermagem, conforme consignado anteriormente.

\section{METODOLOGIA}

Pela razão de estarmos abertos a conhecer a realidade pesquisada, através da experiência que os sujeitos envolvidos vivem em seu processo de trabalho, optamos por trabalhar com a pesquisa qualitativa, considerando que esta nos pareceu a mais apropriada ao objetivo estabelecido.

Leininger apud CIAMPONE (1987) refere-se ao método qualitativo como "aquele que possibilita a observação, documentação, avaliação e interpretação de determinados fenônemos sob estudo".

Também Eisner apud ANDRE (1983) traz como vantagem do dado qualitativo, of fato de que se prestam a capturar os diferentes significados das experiências vividas no ambiente de modo a auxiliar a compreensão das relações entre os indivíduos, seu contexto e suas ações.

Uma vez definido o encaminhamento do trabalho, procuraremos descrever o contexto onde se realizou a pesquisa. Trata-se de uma Rede de Serviços de Atenção Primária à Saúde do município de Botucatu interior do estado de São Paulo. Sua clientela é vinculada ao Sistema Único de Saúde, constituindo-se, em sua maioria, de uma população cujo poder aquisitivo está aquém dos custos para aquisição de medicamentos de forma independente.

Por tratar-se de uma investigação a respeito da compra e distribuição de medicamentos, procurou-se ouvir trabalhadores, nos diversos niveis do fluxo, envolvidas com esses processos.

$\Lambda$ presentaremos esquematicamente, a seguir, o fluxo, ao qual nos referimos para melhor compreensão, de maneira hierárquica: 


\begin{tabular}{|c|}
\hline NIVEL ESTADUAL REGIONAL \\
\hline ERSA - Escritório Regional de Saúde \\
\hline
\end{tabular}

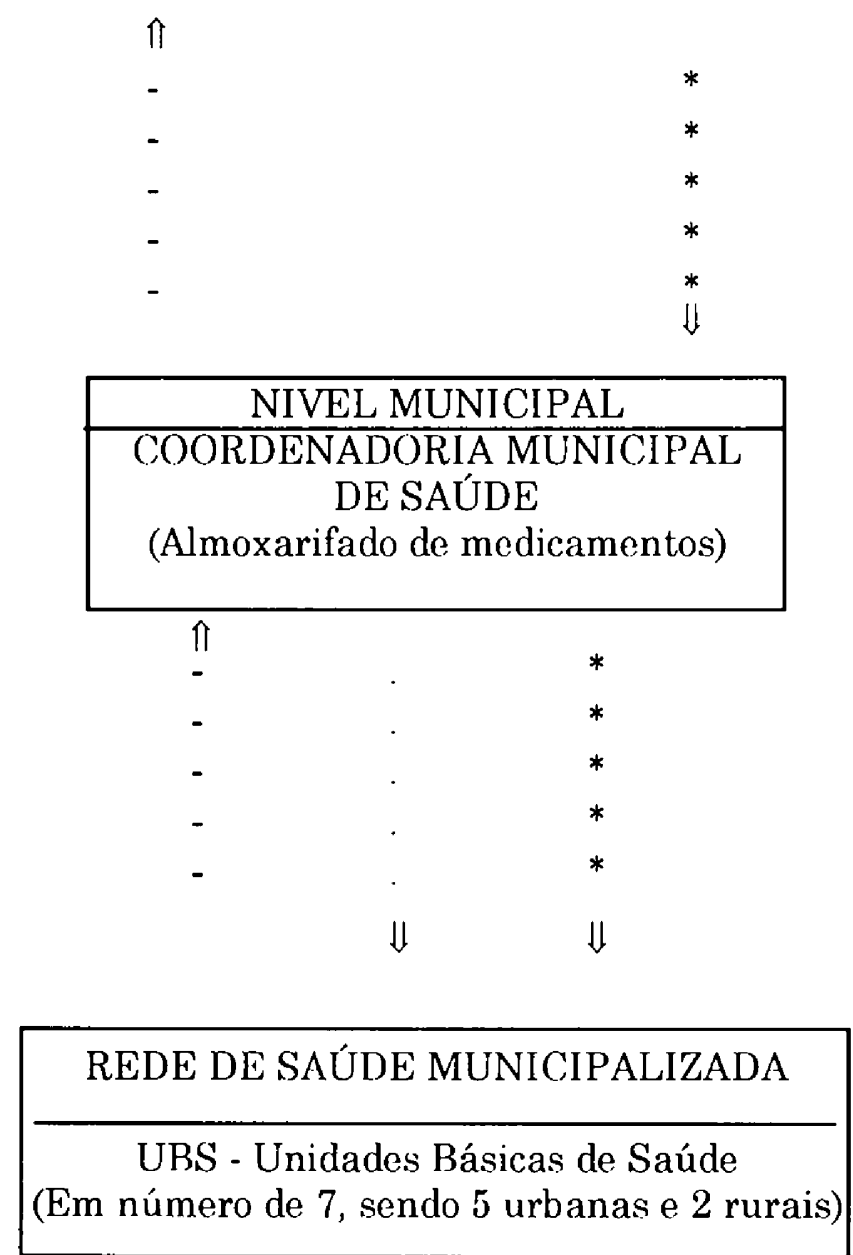

. . . - solicitação das U.B.S.

..... distribuição pela prefeitura

***** distribuição pelo ERSA 
Os dois fornecedores de medicamentos às Unidades Básicas de Saúde UBS, são o Escritório Regional de Saúde - ERSA (estrutura da Secretária de Estado da Saúde) e o ALMOXARIFADO DA COORDENADORIA MUNICIPAL DE SAÚDE (estrutura da Prefeitura Municipal).

Os pedidos de medicamentos (solicitações) partem das UBS e são encaminhados ao almoxarifado da Prefeitura até o dia 10 de cada mês, baseados no consumo de medicamentos. $O$ almoxarifado tem 5 dias para fornecer o pedido às UBS. Os medicamentos seguem com relação de remessa e a funcionária do almoxarifado acompanha a entrega nas UBS.

Quanto ao ERSA, os pedidos são a ele encaminhados através da Coordenadoria Municipal de Saúde, ou seja, um pedido total do município.

Esclarecemos que o ERSA fica sediado na mesma cidade onde foi realizado o estudo das Unidades Municipais de Saúde e que o almoxarifado ao qual nos referimos neste trabalho é destinado especificamente ao setor saúde.

Dado o fluxo apresentado e, dada a intenção de entrevistar pessoas nos diversos níveis do mesmo fluxo, procuramos, inicialmente, entrar em contato com a Diretora do ERSA e solicitamos formalmente que ela nos indicasse duas pessoas que trabalhassem na área de medicamentos, sendo uma a nível de compra e outra a nível de distribuição as UBS ou Municípios. (Nivel Estadual Regional)

Posteriormente, dando continuidade ao trabalho, entramos em contato com o Coordenador Municipal de Saúde, solicitando, formalmente, autorização e indicação do mesmo para que entrevistássemos um funcionário da Coordenadoria de Saúde; um funcionário do Almoxarifado de medicamentos e três funcionários das UBS, sendo um de Unidade de grande porte e dois da Unidade de pequeno ou médio porte. (Nível Municipal)

Tendo obtido resposta afirmativa tanto da Diretora do ERSA, como do Coordenador Municipal de Saúde, marcamos as entrevistas com os respectivos funcionários envolvidos no processo, de acordo com a disponibilidade de cada um, dentro do próprio horário de serviço, após concordância dos mesmos.

Os depoimentos foram gravados em fita cassete, contendo algumas informações funcionais, sendo dirigidas aos informantes duas questões:

\section{Questão 1}

"Qual a sua percepção a respeito dos critérios utilizados no processo de compra e distribuição de medicamentos e sobre a adequação de estoque às demandas?"

\section{Questão 2}

"Como você percebe esse processo de compra e distribuição de medicamentos em relação a algumas facilidades e dificuldades ?" 
As questões foram elaboradas da mesma forma para todos os sujeitos. No entanto, os mesmos foram orientados para enfocar a parte que desenvolvem, baseados na experiência prática, por exemplo, no caso de trabalharem ou só com compra, ou só com a distribuição de medicamentos.

Após a realização das entrevistas, as mesmas foram transcritas das gravaçōes, para posterior análise dos discursos, a ser apresentada mais adiante. Esclarecemos que todos os sujeitos permitiram a gravação das entrevistas.

\section{DADOS DAS PESSOAS ENTREVISTADAS}

O grupo de entrevistados, composto por sete sujeitos, constituiu-se unicamente por pessoas do sexo feminino, na faixa de idade entre 25 e 40 anos aproximadamente, com tempo de experiência na área de medicamentos variável entre seis meses a quatro anos, dos quais forneceremos algumas informações:

SUJEITO 1 local de trabalho: ERSA

$\begin{array}{ll}\text { formação: } & \text { 3. grau (dentista) } \\ \text { cargo: } & \text { Assistente Técnico de Direção } \\ \text { função: } & \text { Distribuição de medicamentos para } \\ & \text { Unidades e Municípios } \\ \text { data e duração da entrevista: } 30 / 06 / 93 \cdot 13 \mathrm{~min} .\end{array}$

SUJEITO 2 local de trabalho:ERSA
formação:
2. grau
cargo:
Diretora Administrativa
função:
Compra cle medicamentos
data e duração da entrevista: 30/06/93 - $15 \mathrm{~min}$.

SUJEITO 3 local de trabalho: Coordenadoria Municipal de Saúde
formação:
3. grau
cargo:
Enfermeira
função:
Organização do almoxarifado
data e duração da entrevista: 12/07/93 - $20 \mathrm{~min}$. 
1. grau

cargo:

Auxiliar de Almoxarifado

função:

Distribuição de medicamentos às Unidades

data e duração da entrevista: 06/07/93 - $17 \mathrm{~min}$.

SUJEITO 5

local de trabalho: Posto Municipal de Saúde (UBS)

formação:

3. grau (enfermeira)

cargo:

Chefe da UBS

função:

Faz pedido de medicamentos

data e duração da entrevista: 06/07/93 - $20 \mathrm{~min}$.

SUJEITO 6

local de trabalho: Posto Municipal de Saúde (UBS)

formação:

3. grau (pedagoga)

cargo:

Visitadora sanitária

função:

Controle e pedido de medicamentos

data e duração da entrevista: 06/07/93 - $20 \mathrm{~min}$.

SUJEITO 7 local de trabalho:Posto Municipal de Saúde (UBS)

formação:

2. grau (professora)

cargo:

Visitadora sanitária

função:

Controle e pedido de medicamentos

data e duração da entrevista: 06/07/93 - $13 \mathrm{~min}$.

\section{ANÁLISE DOS DISCURSOS}

Após a transcrição das entrevistas, demos início a sucessivas leituras dos discursos dos funcionários entrevistados, buscando resgatar unidades significativas sobre o tema para posterior proposicão de categorias.

Embora feita essa divisão ou categorização, notamos que algumas falas inserem-se em dois ou mais temas. Assim sendo, optamos por desenvolvê-las onde estivessem explicitadas com maior ênfase.

A seguir, apresentaremos a interpretação das falas.

Dos sete discursos analisados, emergiram as seguintes categorias: "critérios utilizados na compra e distribuição de medicamentos", "causas de oscilação no fornecimento" e " avaliação do processo". 
A primeira categoria: "critérios utilizados na compra e distribuição de medicamentos" compôs-se das seguintes unidades significativas: critérios de pedidos e compra de medicamentos e questões relativas à distribuição de medicamentos às UBS e aos usuários.

As falas a seguir revelam quais os critérios utilizados para os pedidos e as compras de medicamentos:

S1 ..."o critério que a Secretaria procurava seguir, até agora, seria cobrir os programas, a questão de Tuberculose, de hanseníase é coberto completamente, não há falta desses medicamentos, eles estão conseguindo e seria então através dos programas"...

..."já temos até uma questão de parâmetro de necessidade da população, quer dizer, historicamente, você vai levantando o que é gasto por município, conforme a quantidade de médicos, conforme a demanda atendida"...

S2 ..."tá faltando medicamento da área mental, então a gente resolveu priorizar a área de saúde mental e manter basicamente isso, dai, do recurso que sobra acaba adquirindo pra outros programas”...

S3 ..."na verdade não existe nada padronizado e funciona dependendo da demanda que o médico tiver na unidade"... ..." a gente só corta da unidade quando a gente não tem em estoque,...

S4 ..."trabalha em cima do estoque e do consumo"...

S5 ..."a gente só faz o pedido, de acordo com o consumo da unidade, a gente coloca mais ou menos 25 a $30 \%$ a mais”...

S6 ...," então o estoque eu conto, aí eu vejo no mês anterior o quanto linha, o quanto veio de medicamento, quanto tem agora -é o consumo, o quanto eu gastei no mês, é esse o controle"...

S7 ..."vejo o que eu tinha o mês passado, conto o que eu tenho esse mês e vejo o que eu gastei. Ai, em cima disso eu peco um pouco a mais, uns $20 \% "$...

Outras falas mostram questões relativas a distribuição de medicamentos às UBS e aos usuários: 
.. "a distribuição fica assim, sem você conseguir distribuir adequadamente, porque cê compra o mínimo possível, já com destino certo, nem sempre cobrindo a necessidade"...

S3 ..."quanto à distribuição melhorou muilo depois da criacão do almoxarifado, que a gente contratou uma pessoa só pra fazer isso,...

S4 ..."a quantidade a gente vai olhar, c:omo eu te disse, no estoque, também a gente não vai mandar tudo aquilo que está pedindo, por que tanbém pode até ser que falte pra outro posto,..., não tem jeito de nāo fazer assim, geralmente é o que eles pedem e que realmente precisa"...

S5 ..."a entrega de medicamentos feita pro paciente, é pro mês, mesmo que ele venha com uma receita de medicamento de uso contínuo"...

..." só não entrega se for receita particular, conveniada a gente entrega e tem os critérios pra gente entregar também: tem que ter receita, tem que ter nome na receita, o médico tem que ter assinado, tem que ter (CRM, tem que ter data, se não a gente não entrega"...

..."a população não tem aquela consciência de você tomar o medicamento só com receita médica, é cultural mesmo,..., essa história da gente padronizar só com receita, receita datada, receita assinada, é complicado pra população e é complicado também pra gente"...

S6 ..."sempre eles estão mandando de acordo com o que a gente pede, a quantidade, certinho, eu não vejo assim dificuldade nenhuma, a não ser nos medicamentos que eles tem que comprar, como o diabinese que é difícil, o clorana esse mês não veio"...

..."o medicamento, ele só é entregue com receita médica, então sem receita a genle não entrega o medicamento"...

S7 ..."tem medicamento que é de uso contínuo, ..., então aí a gente dá pro mês, pela data da receita e a pessoa volta buscar"...

Conforme pudemos perceber os critérios de compra de medicamentos baseiam-se ou no consumo das Unidades ou nos programas de saúde. No entanto, o critério relativo a programas parece limitar-se a alguns que tenham tradicão histórica, como é o caso da tuberculose e hanseníase, ou aqueles de caráter mais emergencial como o caso da saúde mental. Convém lembrar que o caráter emergencial em saúde mental, neste caso, deve-se ao fato do ERSA 
ser responsável pela gestão do Hospital Psiquiátrico Cantídeo de Moura Campos que é próprio do Estado, além do Ambulatório de Saúde mental.

Outro aspecto percebido é que o processo conta com alguns critérios de distribuição às Unidades como: consumı mensal, estoque anterior e solicitacão atual e isso de acordo com a quantidade de médicos. Dessa forma é a própria Unidade quem controla suas necessidades por meio de solicitação. Verificouse também que a base de distribuição e consumo é mensal, ou seja, para 30 dias.

Existem ainda critérios de distribuição aos pacientes como: apresentação de receita médica, com identificação, data, CRM, assinatura do profissional. O medicamento é distribuido por 30 dias. Captou-se tamberm a dificuldade da clientela em aceitar esses critérios, dada a prática cultural de auto-medicação.

O sujeito 3 relata que não existe nada padronizado e que depende das demandas das Unidades. Neste sentido vê-se que as Unidades tem relativa autonomia nas solicitaçōes, o que confirma, em parte, o problema já apresentado na Introdução deste estudo relativo ao divorciamento entre a destinação dos produtos ofertados e quadro nosologico do país.

Na segunda categoria proposta, "causas de oscilação no fornecimento", a qual foi construida com base nas unidades significativas: aspectos políticos, aspectos financeiros e aspectos sociais, pudemos verificar algumas interferências que sofre o setor de medicamentos, os quais serão explicitadas a seguir.

Alguns questionamentos revelam aspectos políticos:

S1 ..."a questão da diversidade de produtos,..., estão sempre surgindo novas drogas e dificulta também a questão de aquisição, quer dizer, é toda a polílica mesmo de medicamento, né, que não segue uma norma básica"...

..."o próprio Município, quando ele tem necessidade de fazer uma compra de medicamento, ele tem dificuldade no planejamento,..., ele pode até fazer um estoque, depois receber aquele medicamento, então teria que ser mais clara a política de medicamentos da Secretaria da Saúde também "...

..."houve um momento na política da Secretaria em que ela não iria mais fazer compras de medicamentos, seria repassado verba aos municipios e eles fariam as compras, mas houve uma volta nesse processo e não foi repassado esse dinheiro aos municipios"...

S2 ..."eu acho que a gente tinha que ter maior autonomia de compra, isso implica em ter recurso suficiente"... 
..."mas quando é da Fundação para o Remédio Popular de S.P. FURP, por exemplo, há limitação na quantidade de entrega e no prazo de entrega, então tava sempre faltando medicamentos"...

S5 ..."dependendo da época é mais complicado, é, depende de política, final de ano, começo de ano,..., não é a gente que mexe com isso, a gente só sente no final"...

Abordaremos agora depoimentos referentes a unidade significativa: aspectos financeiros:

S1 ..."a dificuldade maior em relação a medicamentos é custo; realmente o custo do medicamento é muito alto"...

..."cada vez menos a secretaria lá conseguindo cobrir a demanda,..., então, as prefeituras estão cada vez mais assumindo esta atividade"...

S2 ..."além do recurso financeiro, como nós compramos por licitação,..., nós, do estado, normalmente acaba atrasando o pagamento, então, mesmo que na licitação seja solicitado que o preço venha sem inflação, sem previsão inflacionária nós sabemos que os laboratórios imbutem essa inflação no preço, porque eles vão demorar para receber"...

S3 ..."de repente se o médico quer comprar uma coisa muito especifica, com base no critério do dinheiro, se não for dar, a gente corta nesse sentido"...

..."dificuldade de nunca saber o quanto vai ter disponivel pra gastar com medicamentos, e os cortes, dos pedidos da gente, serem feitos em função, claro né, do dinheiro"...

S4 ..."a gente sempre pede essa quantidıde, mas chega lá, eles vão ver se comseguem comprar, em licitação, se dá a verba pra comprar ou não"...

..."quando o estado abastecia a gente, além do que a Prefeitura compra, eu acho que era ótimo trabalhar,não faltava medicamentos"...

S6 ..."aqui, a gente tá bancando o paciente, você acaba entregando toda a receita, por exemplo, de cada dez receitas uma que você não dá completa - é o que eu falo,os médicos, eles usam os 
medicamentos daqui,.., a dificuldade é quando vem de outro lugar: UNESP, UNIMED"...

Vejamos agora algumas considerações acerca dos aspectos sociais:

S1 ..."não adianta nada o serviço de saúde oferecer atendimento médico, o atendimento odontológico, se não tiver como dar continuidade a isso, porque o paciente realmente, cada vez menos, ele tem condição de adquirir o medicamento"...

S5 ..."o problema pra você trabalhar com eles, é você não ter medicamentos pra fornecer e você vê que a pessoa não vai comprar - não vai comprar não - ela não tem condiç̃es para comprar, aí é complicado, porque o serviço não consegue resolver, a mãe também não e, é enrolado mesmo"...

S6 ..." ele vem aqui com a receita - não tem aqui - você tem certeza, tá na cara que ele não vai mesmo em outro lugar,ele não vai em farmácia, ele não compra, ele não tem condições"...

Podemos verificar que os aspectos abordados nas falas acima revelam importantes fatores que intervém no fornecimento de medicamentos e no crescimento da demanda.

$\mathrm{Na}$ fala do sujeito 1 que indica a grande diversidade de fármacos no mercado, notamos a importância de haver um direcionamento nessa política. SARAIVA (1983) já apontava, naquele ano, existirem cerca de 3.496 medicamentos originais e 3.569 similares no mercado brasileiro, num total de 7.065 .

Segundo BERMUDEZ (1992) os medicamentos de nome genérico não são divulgados no Brasil, sendo distribuídos apenas no mercado internacional. Por outro lado, discute desconhecer que a RENAME seja divulgada nos currículos de formação profissional de saúde.

Com relação ao financiamento do setor, pudemos perceber as dificuldades encontradas devido à escassez de verbas e ainda uma certa ambiguidade no aspecto de centralização $X$ descentralização de repasses aos municípios, lembrando que o sujeito 1 referiu "uma volta no processo".

Pudemos ainda resgatar dos discursos, que o município é quem, realmente, está arcando com a maior parte das despesas referentes aos medicamentos.

Cabe ressaltar que, apos desligarmos o gravador, ao final da entrevista, o sujeito 1 informou que a distribuição feita pelo ERSA corresponde a cerca de $15 \%$ do total dos gastos que as prefeituras efetuam com medicamentos. 
As falas relativas aos aspectos sociais dos usuários, revelam a percepção dos sujeitos quanto a queda de poder aquisitivo, pelo qual a população vem passando, não podendo "arcar" com despesas de medicamentos. Percebemos ainda, durante as entrevistas, uma certa angústia nas pessoas sensiveis a esse aspecto, quando não conseguem atender a necessidade da população.

A terceira e última categoria, a qual chamamos "avaliação do processo" foi construída a partir das seguintes unidades significativas: cobertura a população, planejamento e dificuldades técnicas e poder decisório centrado no médico.

Falas que refletem o aspecto de cobertura à população:

S1 ..."aquele que no momento tá mais necessitado éo que a gente socorre primeiro, não tem um planejamento mesmo, devido à falta"... ... "cada vez menos a secretaria tá conseguindo cobrir a demanda”...

S2 ..."nem sempre nós conseguimos comprar tudo aquilo que nós necessitamos, porque o recurso de medicamentos ainda é muito pouco em termos de ERSA"...

S4 ..."geralmente é dificil faltar, pode até acontecer que as vezes saiu mais naquele mês, dai faltou, e eu reponho, mas é dificil, a gente geralmente manda pro mês. todo"...

S5 ..."agente tá conseguindo, a gente tá vendo que a quantidade que a gente tá entregando, tá sendo suficiente,não tá tendo reclamação"...

S6 ..."eu não vi assim muita dificuldade, tem os medicamentos que o paciente tá precisando"...

S7 ..."geralmente vem a quantidade que a gente pede; as vezes falta alguma coisa, demora um pouquinho, mas depois chega"...

Seguem, agora, alguns relatos acerca da unidade significativaplanejamento e dificuldades técnicas:

S1 ..."as Prefeituras estão assumindo esta atividade, de uma maneira não muito bem programada, muitas vezes esse atendimento não corresponde às necessidades mais básicas”... 

mais amplo, acaba influindo da gente não trabalhar direito"...

S3 ..."por a gente não ter uma lista padronizada, fica dificil, porque é aquela coisa - cada um quer uma coisa"...

S4

..."as vezes o remédio tá comprado mas atrissa, então, eu torno ver ondefaltou, e reponho se chegar durante o mês"...

S6 ..."se dá uma zebra que aquele mês saiu mais do que a gente tava esperando, a gente liga no almoxarifado, eles acabam até mandando"...

..."eu prefiro mais contar a farmácia; ..., a funcionária que fica na pós é uma pessoa super responsável, né, qualquer uma, porque é escala, mas sei lá, eu acho que sempre passa alguma coisa, tá, então eu fico na minha, eu acho que é furado isso"...(referia-se ao impresso de controle de saida de medicamentos, implantado na pós-consulta, de onde é distribuida a medicaçâ).

Veremos, agora, alguns depoimentos referentes ao poder decisório centrado no profissional médico:

S3 ..."primeiro, não se conseguiu organizar que medicamentos a gente teria disoniveis, porque cada médico que entra pede uma coisa, então complica o trabalho da gente"...

..."porque o que a gente vê, assim, uns gostam, a maioria dá antibiótico de última geração, tudo super caro, e os outros acabam, sabe, ficando"...

S4 ..."então a gente já sabe, mais ou menos, o que os Postos usam,o que os médicos usam, o que eles preferem"...

S7 ..."as vezes tem um médico que pede mais um medicamento que outro, entendeu, então as vezes começa a sair mais medicamentos do que saia, por vir um determinado médico ou um residente da UNESP"...

Em relação a essas falas, as quais reunimos na categoria "avaliação do processo", percebemos que o fator de cobertura à demanda, parece variar conforme a prescricão dos medicamentos mais básicos e em funcão dos médicos estarem mais "enquadrados" ao serviço, procurando prescrever o que tem na Unidade. 
Em relação ao planejamento, vimos vários aspectos que ainda apresentam-se um pouco confusos, reforçando a importância do mesmo na área de medicamentos. Apesar disso, notamos o esforço das pessoas envolvidas no processo, em melhorar o serviço nos aspectos possiveis. Consideramos positivo o caráter de flexibilidade, quando captamos das falas que os medicamentos são encaminhados na metade do mês, se necessário, ou na chegada de novas cargas, não apresentando muitos entraves burocráticos.

Conforme considerado na introducão deste trabalho, percebemos a confirmação do poder decisório centrado nas mãos do profissional médico, os quais apresentam divergências em suas preferências por um ou outro medicamento.

Daí a importância desses aspectos da política nacional de medicamentos serem amplamente discutidos desde os bancos das Universidades, no sentido de explicitar a política que norteia todo o processo e a quê interesses atende, para que os futuros profissionais possam adquirir uma consciência mais crítica e reflexiva acerca do próprio processo de trabalho.

\section{CONSIDERAÇÕES FINAIS}

Os conteúdos resgatados das falas permitem considerar, que os recursos disponíveis para a área de medicamentos são escassos e as demandas, que necessitam desses insumos, crescentes. Talvez por reflexo da própria implantação recente do Sistema Único de Saúde, estas açōes não se encontram bem planejadas e definidas.

No entanto, consideramos imprescindível a união de todos os scrviços de saúde e Universidades, para que a política de saúde e, consequentemente, a política de medicamentos, possam ter um melhor direcionamento a fim de evitar-se a espoliação do país com perda ou desperdício de recursos e desconcentração de esforços. Faz-se necessário uma melhor coordenação dos recursos humanos envolvidos no trabalho com medicamentos, frente a objetivos claros a serem trabalhados a nível nacional.

Deve-se entender a medicalização da sociedade, em síntese, não como um fenônemo recente da medicina, mas sim como a consequência de seu desenvolvimento histórico como prática, ligada as condições e possibilidades de instauração de um novo tipo de saber médico. (CORDEIRO, 1985)

Conforme afirma SARAIV $\Lambda(1983)$ sabemos que o medicamento, apenas, não será a solução para os problemas de saude pública no Brasil, país gigantesco com grandes variações regionais, estan do o remédio, propriamente, nas melhores condições socio-econômicas de nosso povo, na sua melhor alimentação, moradias com água tratada e esgotos sanitários, essas 
verdadeiras causas do aumento da esperança de vida, assinalada nos últimos anos em diversas partes do globo, ao lado de medidas de ordem profilática como educação, cuidados de higiene, vacinacões, etc.

Concordamos com SARAIVA, quando deixa claro que os problemas de saúde têm sérias raízes em problemas sociais. No entanto, em um Sistema de Saúde organizado em torno do atendimento médico, onde verificamos a crescente prática da medicalização, a variável "medicamento" deve ser considerada na avaliação da consecução de seus objetivos.

Nesse sentido, acreditamos que um esforço mútuo dos profissionais de saúde, aliado a políticas que propiciam uma conscientização crescente dos próprios profissionais, assim como dos usuários do Sistema de Saúde, permitam repensar o rumo das ações de saúde, as consequências de seus direcionamentos, bem como os resultaclos efetivos alcançados com essa prática.

Finalmente, ressaltamos que um país em desenvolvimento, não poderia, ou não deveria, permitir desperdício e abusos em um setor essencial, que, conforme as considerações já expostas, repercutem diretamente sobre aqueles já expropriados das sabidas condições básicas para se alcançar a saúde.

JULIANI, C.M.C.M. Buy and distribution of medicaments for the Basic Unit of Health in municipal district of state Såo Paulo. Rev.Esc.Enf.USP, v.29, n.3, p.267.85, dec. 1995.

The study present analyse the process to buy and distribution of medicaments for the Basic Unit of Health in municipal district of state São Paulo. To achieve some general considerations about the National Politic of Medicaments in Brazil, to emphasize feature relative the its structuration in the Unique System of Health.

UNITERMS:Politic of medicaments. Nursing administration. Material administration. Buy and distribuition of medicaments.

\section{REFERÊNCIAS BIBLIOGRÁFICAS}

ANDRE, M.E.I.A. Texto, contexto e significalos: umas questoes na análise de dados qualitativos. Cad. Pesq. n. 45, p. 66-71, 1983.

BERMUDEZ, J.A.7. Saúde e indústria farmacéutica no Brasil: rumos e desafios. Cadernos da Nona Conferéncia Nacional de Saúde.v. 1, p.17.23. 1992.

BRASIL. Leis, etc. Lei n. 8.080 de 19 de setembro de 1990. Iispoe sobre as condiçoes para a promoção, protecáo e recuperaçăo da saúde, a organizaçono o funcionamento dos serviços correspondentes e dá outras providéncias Diário Oficial da Uniño. Brasília, 20 set. 1990 . Seçăo 1, p.18055-9. 
BRASIL. Ministério da Saúde. Plano Quinquenal de Saúde, 1990/95: a saúde do Brasil novo. Brasília, 1991.

BRASIL. Ministério da Saúde. A assisténcia farmacêutica governamental e a estabilização do mercado de medicamentos. Brasília, 1993.

CIAMPONE, M.H.T. Administraça participativa: análise de uma experiência vivenciada por um grupo, na prática da enfermagem hospitalar. Sáo Paulo, 1987.144 l). Dissertaçăo (Mestrado) - Escola de Enfermagem. Universidade de São Paulo.

CORDEIRO, H. A indústria da saúde no Brasil.2.ed.Rio de Janeiro, Graal, 1985

CUNilA, B.C: de A Saúde: A prioridade esquecida. Petrópolis, Vozes, 1987.

SARAIVA, d L. Polf́tica nacional de medicamentos. Rev. Bras. Educ. Méd v. 7, n. 3, p. 163. $78,1983$. 